\title{
A Importância do Ambiente Virtual de Aprendizagem em um Curso de Graduação com Base nas Percepções de Alunos a Distância
}

\author{
Thaís Tenório¹, Marilda Adlong Laudelino², André Tenório*3
}

\begin{abstract}
${ }^{1}$ Doutora em Química pela Pontifícia Universidade Católica do Rio de Janeiro (PUC-Rio) e pesquisadora do Laboratório de Novas Tecnologias da Universidade Federal Fluminense (UFF/UAB). Rua Mário Santos Braga, s/n, Campos Valonguinho - Niterói - RJ - Brasil. tenoriocalc@gmail.com

${ }^{2}$ Especialista em Planejamento, Implementação e Gestão da Educação a Distância pela Universidade Federal Fluminense (UFF) e professora da rede estadual de São Paulo. Rua Mário Santos Braga, s/n, Campos Valonguinho - Niterói - RJ - Brasil. marildaadlong@ig.com.br

3 Doutor em Física pelo Centro Brasileiro de Pesquisas Físicas (CBPF), pesquisador do Laboratório de Novas Tecnologias da Universidade Federal Fluminense (UFF/Cecierj/UAB), professor do Mestrado Nacional Profissional em Ensino de Física da Universidade Federal do Estado do Rio de Janeiro (Unirio) e professor do Instituto Federal de Educação, Ciência e Tecnologia do Rio de Janeiro (IFRJ). Rua Senador Furtado, 121125, Maracanã - Rio de Janeiro - RJ - Brasil. tenoriocederj@gmail.com
\end{abstract}

\section{Resumo}

Foi investigada a dinâmica de utilização do ambiente virtual de aprendizagem (AVA) de um curso a distância de graduação em Engenharia de uma instituição pública de São Paulo. Cinquenta alunos do primeiro semestre participaram da pesquisa. Quase todos acessavam o AVA, baseado no sistema Canvas, semanalmente. As percepções dos alunos foram conhecidas por meio de questionário. Dúvidas e dificuldades manifestadas em encontros presenciais e virtuais também foram registradas. As dificuldades iniciais de manipulação do AVA puderam ser dirimidas ou mitigadas no decorrer do semestre. Os calouros tinham à disposição diversos recursos. Os preferidos para trabalhar conteúdos eram textos complementares e videoaulas, e para comunicação, videoconferência e e-mail. Não obstante, foi sugerido que houvesse listas de questões com respostas on-line e retorno das correções de exercícios. Para os participantes da pesquisa, o AVA facilitava o acesso à informação e fornecia flexibilidade, mas carecia da possibilidade de comunicação imediata com tutores nos momentos desejados.

Palavras-chave: Educação a distância; Ambiente Virtual de Aprendizagem; Aluno. 


\title{
The View of E-Learning Undergraduate Students on the Virtual Learning Environment
}

\begin{abstract}
The utilization dynamics of the virtual learning environment (VLE) employed of graduation engineering course of a public institution in São Paulo State was investigated. Fifty students on the first semester of the course have participated on the research. Almost all of them accessed weekly VLE based on Canvas learning management system. Doubts and difficulties expressed by the students during face to face and virtual meetings were also recorded. Initial difficulties related to the VLE use could be solved or mitigated during the semester. Many learning resources were made available to students in the VLE. According to the students' opinion, complementary literature, video lessons and email were the preferred type studying material. Yet, it was suggested the use of worksheets with answers available online and feedbacks to the correction. To them, the VLE facilitates access to information and provides flexible studying schedules. However, the lack of on-demand live communication with tutors was considered a drawback.
\end{abstract}

Keywords: Distance learning; Virtual Learning Environment; Student. 


\section{Introdução}

A humanidade sempre procurou se comunicar, seja por gestos, fala ou escrita (Gaspar, 2003). Mesmo uma criança, antes de aprender a falar e a escrever a língua materna, já é capaz de se expressar por diversas formas.

No ensino-aprendizagem, a comunicação também é essencial (Tenório, Souto, \& Tenório, 2014a). Prover a professores e a alunos meios de acesso à informação e à comunicação com uso da tecnologia parece ser um modo de modernizar as relações entre escola e sociedade (Kenski, 2004).

Nos últimos anos, houve a proliferação dos computadores pessoais, que, além de possibilitar maior integração entre vários recursos, também possuem programas específicos para interação (Trabucho, 2008). "A evolução e a disseminação dessas tecnologias alcançaram um nível em que é difícil encontrar pessoas que ainda não tiveram direta ou indiretamente contato com elas, independente da classe social, do nível de escolaridade e do local onde moram" (Barbosa, \& Silva, 2011, p. 2).

A educação a distância (EaD) cresceu muito nos últimos anos, inclusive no Brasil. A facilidade de acesso à tecnologia contribuiu para tal expansão, pois tornou a EaD mais atrativa pelo emprego de ferramentas baseadas na internet (Belloni, 2002; Maia, 2002; Ribeiro, Mendonça, \& Mendonça, 2007).

Apesar da distância física entre professor e aluno, em geral, um curso a distância contemporâneo não se caracteriza pela falta de diálogo (Santos, 2011). Na EaD, a comunicação pode ocorrer independentemente de momentos e lugares preestabelecidos. Essa flexibilidade foi acentuada pela evolução de tecnologias de informação e comunicação (TICs) baseadas em mídias digitais.

Empregar esses recursos em um contexto educacional provoca mudanças no processo de ensino-aprendizagem, porque as novas gerações de educandos não necessitam mais de um educador para transmitir informações mas, sim, para orientar e mediar a construção do conhecimento (Belloni, 2005; Bévort, \& Belloni, 2009; Sousa, Moita, \& Carvalho, 2011; Tenório et al., 2014a; Teixeira, Sales, Tenório, \& Tenório, 2015).

Entre os recursos tecnológicos atuais, o ambiente virtual de aprendizagem (AVA) se destaca (Campos, Costa, \& Santos, 2007; Messa, 2010; Tenório, Ferreira, Almeida, 
Zucon, \& Tenório, 2014b). Ele funciona como sala de aula virtual para cursos (Ribeiro et al., 2007) e serve para o apoio à EaD contemporânea, ao facilitar a comunicação e o desenvolvimento de atividades por alunos, tutores, professores e administradores. Segundo o Ministério de Educação e Cultura, os AVAs são:

[...] programas que permitem o armazenamento, a administração e a disponibilização de conteúdos no formato web. Dentre esses, destacam-se: aulas virtuais, objetos de aprendizagem, simuladores, fóruns, salas de bate-papo, conexões a materiais externos, atividades interativas, tarefas virtuais (webquest), modeladores, animações, textos colaborativos (wiki) (Brasil, 2007, p. 11).

Existem diversas vantagens em empregar as funcionalidades de um AVA para a EaD (Campos et al., 2007; Ribeiro et al., 2007; Tenório et al., 2014b). Por exemplo:

- apresentar materiais didáticos de modo organizado, criativo e atrativo, de modo a estimular e motivar a aprendizagem;

- armazenar os materiais didáticos, os debates do grupo e as avaliações dos alunos;

- auxiliar na administração e no acompanhamento da participação dos alunos;

- possibilitar ao educador acompanhar todos os cursistas no processo de ensino-aprendizagem;

- $\quad$ permitir ao educador dar atenção individual ao cursista;

- possibilitar a avaliação a distância do cursista;

- $\quad$ promover a interação do aluno com o curso;

- facilitar a interação entre os cursistas e deles com o tutor;

- permitir ao cursista controlar seu ritmo de aprendizagem dentro dos critérios estabelecidos no curso.

Alguns autores já investigaram o emprego de AVAs em cursos de graduação a distância. Destacam-se as pesquisas de Bezerra e Brito (2013), Lévy (2003), Messa (2010), Tenório et al. (2014b) e Valentini, \& Soares (2010). Contudo, poucos consideraram a percepção de calouros. 
De acordo com Lévy (2003), o AVA beneficia a comunicação na EaD. Ele permite a troca contínua de informações de forma flexível, e favorece a interação entre os participantes, a autonomia do aluno e a construção coletiva do conhecimento.

Valentini e Soares (2010) também apontaram os AVAs como fundamentais para a EaD. "As salas de aula criadas pelas máquinas cerebrais - os ambientes virtuais de aprendizagem - gradativamente parecem constituir respostas adequadas a algumas exigências que a era da informação coloca" (Valentini, \& Soares, 2010, p. 23).

Tenório et al.(2014b) investigaram as percepções de nove tutores de cursos de graduação a distância de uma instituição privada do estado de São Paulo. Segundo a pesquisa, o AVA foi considerado por $89 \%$ o principal recurso da EaD, ao proporcionar um espaço virtual de aprendizagem e compartilhamento de informações. "Ao comparar o ensino a distância e o presencial, ele equivaleria à sala de aula. No AVA, tutor e alunos, mesmo separados na distância e no tempo, constroem o conhecimento interativamente" (Tenório et al., 2014b, p. 51).

A importância de um AVA largamente empregado em um curso a distância de graduação em Engenharia de uma instituição pública foi analisada com base na percepção de calouros. A investigação objetivou responder, no âmbito dos participantes do estudo, a três questões norteadoras:

- Quais são as expectativas de alunos ao empregarem AVAs?

- Como AVAs influenciam na aprendizagem?

- Quais características dos AVAs chamam atenção de alunos a distância?

\section{Metodologia}

A pesquisa analisou, com base nas percepções de alunos do primeiro semestre, um AVA no contexto educacional de um curso de graduação a distância. $O$ intuito foi identificar as expectativas dos calouros ao empregar um AVA, seus efeitos sobre a aprendizagem e a interação a distância, suas características positivas e negativas, as dificuldades em sua manipulação e suas principais ferramentas. 


\subsection{Contexto do Estudo}

Alunos de três turmas de graduação a distância em Engenharia, de um mesmo pólo, perfizeram a população da pesquisa. Cada turma tinha 18 pessoas, contabilizando 54 alunos. Essas eram as primeiras turmas da graduação a distância em Engenharia da instituição.

O curso era fundamentado no emprego extensivo do AVA e valorizava a autonomia do aluno. Cada disciplina contava com encontros semanais com o tutor. Alternadamente, em uma semana, o encontro era presencial no laboratório de informática do pólo e, na outra, virtual, por meio das ferramentas interativas GoToMeeting e TERF, ambos sistemas de videoconferência, acessíveis por meio do AVA institucional. O polo, pertencente a uma universidade pública estadual, era localizado no município de São Paulo.

Todas as disciplinas de primeiro período do curso seguiam o mesmo modelo de implantação e compartilhavam o AVA, baseado no Canvas, sistema proprietário da empresa inglesa Instructure. Para cada uma, materiais eram disponibilizados pelos professores das disciplinas, em geral, videoaulas, textos complementares, animações, atividades para portfólios, listas de questões e FAQs. Os alunos contavam ainda com ferramentas de comunicação como videoconferência, fórum, e-mail e bate-papo. Por meio delas, ocorria a interação entre alunos e deles com o tutor. Os professores participavam ocasionalmente das discussões.

Aos estudantes era solicitado que desenvolvessem atividades pelo AVA, em especial, assistir videoaulas, ler textos complementares e elaborar portfólios. Tomar parte nos encontros presenciais e virtuais também era requerido. O tutor exercia orientação pedagógica, suporte tecnológico e apoio socioafetivo. Os professores das disciplinas prestavam auxílio didático de conteúdo.

\subsection{Sujeitos dos Participantes}

Participaram da pesquisa 50 alunos, o que totalizou 92\% da população analisada. A amostra, considerada intencional (Marconi, \& Lakatos, 2003), tinha como característica relevante a condição de o estudante a distância ser calouro. Dos participantes, 34 (68\%) 
eram homens e $16(32 \%)$, mulheres. A maioria (26; 52\%) tinha de 21 a 30 anos (Tabela 1).

Também a maioria (33; 66\%) nunca tinha realizado curso a distância antes. Os demais haviam feito cursos de especialização (5;10\%), graduação $(2 ; 4 \%)$, extensão $(1 ; 2 \%)$ e de outra natureza $(9 ; 18 \%)$, de áreas variadas: Ciências Humanas e Sociais (10) e Ciências Exatas e da Natureza (7). Tais cursos pregressos foram efetuados em instituições diversas, públicas (9) e privadas (8). Os sistemas de gerenciamento de AVAs utilizados nesses cursos, segundo os alunos, eram Moodle (4), BlackBoard (4) e AulaNet (1). Os demais não souberam responder.

Tabela 1: Faixa etária dos alunos pesquisados.

\begin{tabular}{r|r|r}
\hline Faixa etária & Total & Percentual \\
\hline 18 a 20 anos & 2 & $4 \%$ \\
\hline 21 a 25 anos & 11 & $22 \%$ \\
\hline 26 a 30 anos & 15 & $30 \%$ \\
\hline 31 a 35 anos & 4 & $8 \%$ \\
\hline 36 a 40 anos & 8 & $16 \%$ \\
\hline 41 a 45 anos & 2 & $4 \%$ \\
\hline 46 a 50 anos & 3 & $6 \%$ \\
\hline 51 a 55 anos & 5 & $10 \%$ \\
\hline
\end{tabular}

Os alunos classificaram a experiência nos cursos a distância antecedentes como ótima (6), boa (10) e razoável (1). O fato de esses egressos terem tido experiências positivas pode ter influenciado na opção de realizar outro curso na modalidade a distância.

O ponto de acesso à internet mais frequentemente usado era o computador de casa $(32 ; 64 \%)$, seguido do smartphone em casa $(10 ; 20 \%)$ ou fora de casa $(5 ; 10 \%)$ e do computador da instituição de trabalho (3; 6\%). Computadores em casa de parentes ou amigos, lan houses e pontos de acesso gratuitos não foram citados. Apenas 28 participantes responderam qual seria a velocidade do ponto de acesso à internet $(1,2$, $4,5,10,11,30$ e $35 \mathrm{Mb} / \mathrm{s}$ ). A média das velocidades foi 9,1 Mb/s, considerada boa. A 
disponibilidade restrita de conexões internet de banda larga é um entrave ao emprego de TICs e, por conseguinte, à EaD contemporânea (Tenório et al., 2014b). O fato de os alunos disporem de uma boa conexão, provavelmente, favorece a aprendizagem a distância.

\subsection{Instrumentos de Coleta de Dados}

A pesquisa de natureza aplicada, abordagem qualitativa e descritiva seguiu o procedimento metodológico de estudo de caso (Gil, 1999; Marconi, \& Lakatos, 2003).

Os dados foram coletados por meio de observação participante, instrumento de observação direta intensiva (Marconi, \& Lakatos, 2003), e de um questionário, instrumento de observação direta extensiva (Gil, 1999).

Em um primeiro momento, foram feitas observações dos encontros presenciais no laboratório de informática, nos meses de julho a outubro de 2014, período correspondente a um semestre letivo. Registraram-se o desempenho dos alunos, as dúvidas e as dificuldades pertinentes ao uso do AVA e suas ferramentas. Tal verificação também foi feita nos encontros virtuais durante o mesmo período.

No último encontro presencial antes das provas finais das disciplinas (em outubro de 2014), os calouros responderam a um questionário sobre o AVA, aplicado pessoalmente no polo da instituição e elaborado pelos autores. Ele continha perguntas com respostas fechadas (de múltipla escolha), semifechadas e abertas (discursivas).

\subsection{Análise dos Dados}

A análise dos dados visou identificar as dificuldades e as facilidades do uso do AVA segundo os calouros, além de seus aspectos mais relevantes para a aprendizagem. Também buscou conhecer sugestões, com o intuito de apontar possíveis melhorias a serem feitas nesses ambientes.

Os dados obtidos pelos questionários em perguntas com respostas fechadas ou semifechadas foram tabulados e analisados. As perguntas com respostas abertas foram sistematizadas e categorizadas em núcleos de significado e examinadas conforme a análise de conteúdo de Bardin (Bardin, 1998; Câmara, 2013). 


\section{Resultados e Discussão}

A seção de resultados e discussões foi dividida em duas partes. Na primeira, foram relatadas as principais observações feitas durante os encontros presenciais e virtuais. Na segunda, os dados colhidos pelo questionário foram reportados e analisados.

\subsection{Observações sobre a Manipulação do AVA pelos Alunos}

Nos encontros presenciais e virtuais, o desempenho dos alunos, as dúvidas e as dificuldades referentes ao uso do AVA e suas ferramentas foram observados nos meses de julho a outubro de 2014.

Em princípio, diversos calouros relataram problemas de acesso, provavelmente, porque o AVA ainda estava em término de construção no início do curso (em julho de 2014). Outra dificuldade frequente envolveu o áudio das ferramentas do ambiente, com configuração incompatível aos recursos computacionais de muitos alunos. As dificuldades foram sanadas ainda no primeiro mês do curso, com a finalização do AVA e a disponibilização de instruções de configuração dos computadores dos usuários.

Os primeiros encontros virtuais ocorreram por meio do GoToMeeting, sistema de videoconferência destinado a reuniões de grupos pequenos. Muitos tiveram problemas em permanecer conectados, quando todos os alunos da turma estavam presentes, devido à conexão de internet lenta, o que os obrigava a abandonar constantemente as discussões. Quando o TERF, outro sistema de videoconferência, foi disponibilizado, os problemas de comunicação foram progressivamente amenizados.

Após quatro meses do início do curso, o e-mail ainda era a ferramenta de comunicação com o tutor mais usada nos dias sem encontros presenciais ou virtuais. Os alunos empregavam-no para enviar dúvidas de conteúdo ou solicitar informações. No AVA, as ferramentas de comunicação eram pouco aproveitadas pelos alunos. Quando usadas, muitos se limitavam a discutir as videoaulas do curso. 


\subsection{O AVA com Base nas Percepções dos Alunos}

Todos os alunos (100\%) consideravam importante usar a internet como forma de apoio às disciplinas, mas apenas 35 (70\%) justificaram a razão para isso. Essas respostas foram organizadas e categorizadas em núcleos de significado de acordo com análise de conteúdo.

A maioria dos estudantes $(26 ; 52 \%)$ descreveu a internet como um meio de acesso à informação e à pesquisa que ajudaria na aprendizagem e no entendimento dos conteúdos dos encontros presenciais. Os demais citaram as diferentes TICs e seu incentivo à interação $(5 ; 10 \%)$ e a possibilidade de a internet favorecer o desenvolvimento pessoal (4; 8\%). Belloni (2002), Kenski (2004) e Maia (2002) destacaram as diversas possibilidades trazidas pela internet para a aprendizagem, como aquelas que envolvem pesquisa e troca de experiências.

Os respondentes foram unânimes em dizer que o AVA facilitaria o aprendizado, mas apenas $36(72 \%)$ explicaram por quê (Quadro 1 ). Dois (4\%), contudo, deram justificativas disparatadas, desconsideradas na categorização dos dados. As demais respostas foram agrupadas em núcleos de significado, conforme análise de conteúdo.

Quadro 1: Justificativas de o AVA facilitar a aprendizagem.

\begin{tabular}{|c|c|}
\hline Acessibilidade à informação & Flexibilidade \\
\hline 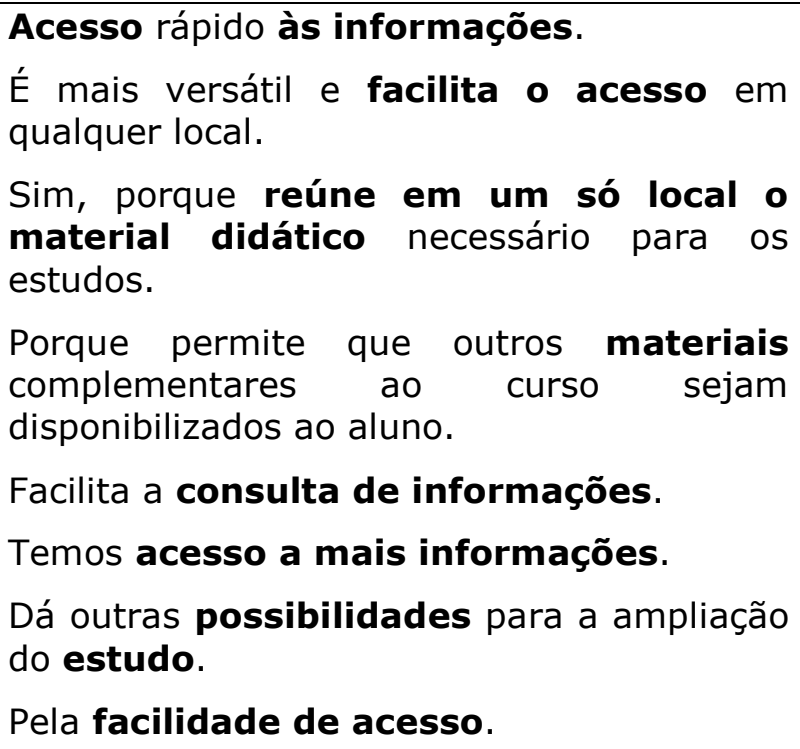 & $\begin{array}{l}\text { Hoje em dia, é essencial o ambiente virtual com } \\
\text { flexibilidade de horário para tudo. } \\
\text { Posso fazer meus horários de estudo. } \\
\text { Pela disponibilidade de estudar nos horários } \\
\text { que tenho disponíveis. } \\
\text { A facilidade de assistir às aulas no momento } \\
\text { em que quiser. } \\
\text { Porque possibilita revisões infinitas vezes, serve } \\
\text { como consulta em qualquer momento. } \\
\text { Posso estudar no horário que é conveniente } \\
\text { para mim. } \\
\text { Porque posso acessar quando precisar (a } \\
\text { qualquer momento) e com comodidade. } \\
\text { Por ser muito dinâmico. }\end{array}$ \\
\hline Auxílio à aprendizagem & Facilidade em sanar dúvidas \\
\hline
\end{tabular}




\begin{tabular}{|c|c|}
\hline $\begin{array}{l}\text { Porque é um modo de aprendizado mais } \\
\text { eficiente e duradouro. }\end{array}$ & $\begin{array}{l}\text { Nos ajuda a discutir os temas, eliminando } \\
\text { algumas dúvidas. }\end{array}$ \\
\hline $\begin{array}{l}\text { Porque existe uma gama de aprendizagem } \\
\text { para as diferentes pessoas. }\end{array}$ & $\begin{array}{l}\text { Porém ainda assim é necessário ter alguém para } \\
\text { sanar as dúvidas. }\end{array}$ \\
\hline $\begin{array}{l}\text { Outra forma de melhorar a minha } \\
\text { aprendizagem. } \\
\text { Promove autodidatismo. } \\
\text { Você tem que descobrir sozinho o que } \\
\text { fazer e quanto tempo tem para isso. } \\
\text { Pois facilita os encontros presenciais. }\end{array}$ & $\begin{array}{l}\text { Eu consigo acessar diversas formas de abordar } \\
\text { algum assunto no qual estou com } \\
\text { dificuldade. } \\
\text { Possibilidade de pesquisa sem sair de seu } \\
\text { ambiente. } \\
\text { É possível obter explicações diferentes sobre } \\
\text { o mesmo assunto. }\end{array}$ \\
\hline Disponibilidade de videoaulas & Boa \\
\hline $\begin{array}{l}\text { Porque posso assistir às aulas onde eu } \\
\text { estiver, não precisando me locomover ou sair } \\
\text { de casa para estudar. } \\
\text { Existe a possibilidade da repetição- } \\
\text { exibição em qualquer local. } \\
\text { Pela oportunidade de rever as aulas. } \\
\text { A tecnologia permite ver e rever as aulas } \\
\text { em vídeo, auxiliando a fixar conteúdos. } \\
\text { Ainda não sei responder com muita precisão. } \\
\text { Mas é bom ter todas as aulas em um único } \\
\text { lugar, organizado e com espaço para } \\
\text { resposta. }\end{array}$ & $\begin{array}{l}\text { Desde que seja bem feito e que todos } \\
\text { consigam interagir. } \\
\text { Porque ainda é um sistema em construção } \\
\text { (Canvas/TERF). O Moodle é uma plataforma } \\
\text { muito mais madura. }\end{array}$ \\
\hline
\end{tabular}

Muitos apontaram o acesso à informação $(8 ; 16 \%)$ e a flexibilidade $(8 ; 16 \%)$ como benéficos à construção do conhecimento. Campos et al. (2007) também destacaram essas características como essenciais aos AVAs.

Seis (12\%) dos estudantes afirmaram que o AVA auxiliaria a aprendizagem de múltiplas formas, como promovendo a autonomia, essencial para a EaD (Dias, 2003). Cinco (10\%) assinalaram a facilidade em sanar dúvidas por meio de consulta de materiais, pesquisa ou debate. Cinco (10\%) mencionaram a disponibilidade de videoaulas como uma característica importante do AVA analisado.

A necessidade de o AVA ser bem elaborado foi mencionada por dois alunos (4\%). A percepção coaduna-se com estudo de Tenório et al. (2014b) em que, segundo as perspectivas de nove tutores de cursos de graduação de uma universidade de São Paulo, um AVA bem construído influencia na participação dos cursistas a distância. 
Para 44 pesquisados ( $88 \%$ ), a disponibilidade de material digital melhora muito a qualidade dos encontros presenciais, provavelmente por permitir o estudo prévio dos conteúdos a serem discutidos.

Tabela 2: Ferramentas de comunicação disponíveis no AVA e utilizadas pelos alunos.

\begin{tabular}{c|r|r}
\hline Ferramentas de comunicação do AVA & Total & Percentual \\
\hline E-mail & 37 & $74 \%$ \\
\hline Fórum & 35 & $70 \%$ \\
\hline Correio de mensagem do AVA & 30 & $60 \%$ \\
\hline Bate-papo & 26 & $52 \%$ \\
\hline Hyperlink para videoconferência & 25 & $50 \%$ \\
\hline Telefone VoIP (via internet) & 10 & $20 \%$ \\
\hline Blog & 3 & $6 \%$ \\
\hline Hyperlink para o Twitter & 2 & $4 \%$ \\
\hline Hyperlink para o Facebook & 2 & $4 \%$ \\
\hline Comunico-me apenas pessoalmente & 4 & $8 \%$ \\
\hline
\end{tabular}

O AVA institucional era acessado, diariamente, por 24 alunos (48\%), em dias alternados, por 13 (26\%), três vezes por semana, por dez (20\%), aos finais de semana, por um ( $2 \%)$ e apenas em época de provas, por um (2\%). A consulta frequente ao AVA pela maioria dos alunos coincide com as observações de diversos autores, que o descrevem como uma sala de aula virtual (Kenski, 2004; Campos et al., 2007; Tenório et al., 2014b).

O curso oferecia diversas ferramentas de comunicação (Tabela 2). Predominantemente, eram usados e-mail (37) e fórum (35). Blog (3), Twitter (2) e Facebook (2) eram menos comuns. Apesar das inúmeras ferramentas, quatro alunos preferiam manter a comunicação pessoalmente, porque o curso oferecia a alternativa de encontros presenciais quinzenais. Provavelmente, essa possibilidade desestimulava a comunicação virtual, principalmente, para quem preferia a pessoal.

Para a comunicação com os colegas de curso, os alunos preferiam videoconferências (20) e e-mails (17) (Tabela 3). 
A videoconferência figurou como uma TIC favorita, talvez, por permitir comunicação em tempo real com menos limitações à metalinguagem humana (Gutierrez, 2006). O fato de já ser utilizada nos encontros virtuais também pode ter influenciado os alunos. Muitos gostavam do e-mail, quiçá, pelo fato de essa forma de comunicação ser assíncrona (Farias, 2013; Nascimento, \& Filho, 2002) e bastante disseminada (Brito, 2003).

Tabela 3: Ferramentas preferidas pelos alunos para interação com colegas de curso.

\begin{tabular}{c|r|r}
\hline Ferramentas de comunicação preferidas & Total & Percentual \\
\hline Videoconferência & 20 & $40 \%$ \\
\hline E-mail & 17 & $34 \%$ \\
\hline Telefone VoIP (via internet) & 3 & $6 \%$ \\
\hline Fórum & 3 & $6 \%$ \\
\hline Bate-papo & 3 & $6 \%$ \\
\hline WhatsApp & 2 & $4 \%$ \\
\hline Facebook & 1 & $2 \%$ \\
\hline Correio de mensagem do AVA & 1 & $2 \%$ \\
\hline Blog & 0 & $0 \%$ \\
\hline Twitter & 0 & $0 \%$ \\
\hline
\end{tabular}


Tabela 4: Recursos mais utilizados pelos alunos para trabalhar os conteúdos didáticos.

\begin{tabular}{|c|c|c|}
\hline Recursos para trabalhar conteúdos & Total & Percentual \\
\hline Texto complementar & 43 & $86 \%$ \\
\hline Portfólio & 30 & $60 \%$ \\
\hline Youtube & 26 & $52 \%$ \\
\hline Fórum & 25 & $50 \%$ \\
\hline E-mail & 23 & $46 \%$ \\
\hline Google Drive (antigo Google Docs) & 19 & $38 \%$ \\
\hline Videoconferência & 19 & $38 \%$ \\
\hline Questionário & 13 & $26 \%$ \\
\hline Bate-papo & 12 & $24 \%$ \\
\hline Correio de mensagem do AVA & 11 & $22 \%$ \\
\hline Animação & 10 & $20 \%$ \\
\hline Hyperlink & 10 & $20 \%$ \\
\hline Mural & 10 & $20 \%$ \\
\hline Avaliação ou tarefa on-line & 10 & $20 \%$ \\
\hline$F A Q$ (perguntas e respostas) & 7 & $14 \%$ \\
\hline Slideshare & 7 & $14 \%$ \\
\hline Pesquisa de opinião & 4 & $8 \%$ \\
\hline Simulação & 2 & $4 \%$ \\
\hline Telefone VoIP & 2 & $4 \%$ \\
\hline Blog & 2 & $4 \%$ \\
\hline Wiki & 2 & $4 \%$ \\
\hline Facebook & 1 & $2 \%$ \\
\hline Videoaula & 1 & $2 \%$ \\
\hline Dropbox & 1 & $2 \%$ \\
\hline Twitter & 0 & $0 \%$ \\
\hline
\end{tabular}

Os recursos de maior importância utilizados para trabalhar os conteúdos didáticos do curso, nas percepções dos alunos, eram textos complementares $(43 ; 86 \%)$, portfólio $(30 ; 60 \%)$, Youtube $(26 ; 52 \%)$ e fórum $(25 ; 50 \%)$ (Tabela 4). Apesar de o AVA ainda 
não ter disponibilizado todos os recursos, notou-se o uso de uma boa variedade para a aprendizagem.

Os alunos priorizam a utilização do AVA para acessar textos complementares e elaborar os portfólios recomendados no curso. É muito importante ter cuidado ao preparar o material didático da EaD porque tal recurso transmite a concepção pedagógica, capaz de orientar o processo de ensino-aprendizagem.

Tabela 5: Ferramentas que mais contribuem para a aprendizagem.

\begin{tabular}{c|r|r}
\hline Ferramentas para a aprendizagem & Total & Percentual \\
\hline Youtube & 32 & $64 \%$ \\
\hline Videoconferência & 23 & $46 \%$ \\
\hline E-mail & 20 & $40 \%$ \\
\hline Fórum & 19 & $38 \%$ \\
\hline Bate-papo & 16 & $32 \%$ \\
\hline Google Drive & 16 & $32 \%$ \\
\hline Portfólio & 13 & $26 \%$ \\
\hline Correio de mensagem do AVA & 9 & $18 \%$ \\
\hline Slideshare & 9 & $18 \%$ \\
\hline Hyperlink & 8 & $16 \%$ \\
\hline FAQ (perguntas e respostas) & 7 & $14 \%$ \\
\hline Avaliação ou tarefa on-line & 7 & $14 \%$ \\
\hline Wiki & 5 & $10 \%$ \\
\hline Telefone VoIP & 4 & $8 \%$ \\
\hline Blog & 4 & $8 \%$ \\
\hline Facebook & 4 & $8 \%$ \\
\hline Mural & 2 & $4 \%$ \\
\hline Twitter & 1 & $2 \%$ \\
\hline Videoaula & $2 \%$ \\
\hline
\end{tabular}

A maioria dos alunos $(33 ; 66 \%)$ considerava as aulas disponibilizadas boas. Dez achavam ótimas e sete, razoáveis. Contudo, o acesso às videoaulas pelo AVA figurava em segundo plano, tendo sido aventado por apenas um participante (Tabela 5). Isso se 
deve ao fato de muitos assistirem às aulas diretamente pelo Youtube $(25 ; 50 \%)$, onde também estavam disponíveis. Por essa razão, muitos (32;64\%) citaram o Youtube como a ferramenta que mais contribui para a aprendizagem (Tabela 5). O site também oferece a possibilidade de pesquisa e acesso a materiais complementares buscados pelos próprios estudantes.

Outras ferramentas muito citadas foram a videoconferência (23;46\%), o e-mail $(20 ; 40 \%)$, o fórum $(19 ; 38 \%)$, o bate-papo $(16 ; 32 \%)$ e o Google Drive $(16 ; 32 \%)$. Tais TICs favorecem a construção coletiva do conhecimento e constituem o esteio de muitos cursos da EaD contemporânea. Todos os meios de comunicação possíveis devem ser utilizados para acompanhar os alunos a distância. Nesse sentido, a equipe desenvolvedora do material didático deve estimular uma combinação de diversas ferramentas veiculadas pelas tecnologias mais convenientes de acordo com o perfil do usuário, de modo que os alunos aproveitem os benefícios pedagógicos de cada TIC.

A grande importância para a aprendizagem atribuída à videoconferência e ao e-mail deve advir do fato de o curso usar tais ferramentas para, respectivamente, promover encontros virtuais e passar informes.

O FAQ, espaço destinado a perguntas e respostas, era bastante usado para trabalhar conteúdos por sete alunos (Tabelas 4 e 5) e ajudava 29 (58\%) a eliminar suas dúvidas, embora não fizesse diferença para 20.

Tabela 6: Expectativa do aluno ao empregar o AVA.

\begin{tabular}{c|r|r}
\hline Expectativas dos alunos ao usar o AVA & Total & Percentual \\
\hline Recorrer a uma forma de aprendizagem alternativa ao estudo presencial & 39 & $78 \%$ \\
\hline Acessar conteúdos disciplinares adicionais & 34 & $68 \%$ \\
\hline Ter a oportunidade de aprofundar o aprendizado & 29 & $58 \%$ \\
\hline Interagir com os colegas para estudar em grupo on-line & 17 & $34 \%$ \\
\hline Informar-me sobre datas de trabalhos e provas & 13 & $26 \%$ \\
\hline Gosto de usar o computador em tudo o que faço & 13 & $26 \%$ \\
\hline Aprender melhor que em sala de aula & 10 & $20 \%$ \\
\hline Prefiro não usar o AVA & 1 & $2 \%$ \\
\hline Apenas acesso o AVA para poder me graduar & 0 & $0 \%$ \\
\hline
\end{tabular}


A principal expectativa dos alunos ao empregar o AVA era utilizar uma forma de aprendizagem alternativa ao estudo presencial (39; 78\%) (Tabela 6). Atualmente, muitos indivíduos buscam a EaD como modalidade para formação, atualização ou aperfeiçoamento devido a sua maior flexibilidade em comparação à educação presencial (Belloni, 2002; Kenski, 2004; Trabucho, 2008), mas outros também buscam aliar o estudo à evolução tecnológica (Lévy, 2003).

Outras expectativas comuns eram acessar conteúdos disciplinares adicionais (34; $68 \%$ ) e ter oportunidade de aprofundar o aprendizado (29; 58\%) (Tabela 6). Em geral, os AVAs reúnem todos os materiais de estudo e as atividades de um curso a distância, sem abrir mão da plasticidade no processo de ensino-aprendizagem. Isso favorece uma apresentação padronizada, mas não monolítica, dos conteúdos armazenados, ao mesmo tempo em que permite a tutores e alunos propor e disponibilizar materiais adicionais, de forma contextualizada, às dinâmicas das discussões.

Tabela 7: Dificuldades dos alunos em manipular o AVA.

\begin{tabular}{|c|c|c|}
\hline Dificuldades de manipulação do AVA & Total & Percentual \\
\hline É difícil usar as ferramentas de comunicação do AVA & 8 & $16 \%$ \\
\hline É difícil encontrar as tarefas a serem realizadas & 5 & $10 \%$ \\
\hline Não consigo me comunicar com o tutor no AVA & 5 & $10 \%$ \\
\hline A página de acesso ao AVA tem uma configuração confusa & 4 & $8 \%$ \\
\hline É difícil encontrar os materiais de estudo & 4 & $8 \%$ \\
\hline Não consigo me comunicar com os colegas de curso no AVA & 4 & $8 \%$ \\
\hline O acesso ao AVA é muito lento & 2 & $4 \%$ \\
\hline É difícil enviar as tarefas & 2 & $4 \%$ \\
\hline É difícil visualizar as notas ou os feedbacks do tutor & 2 & $4 \%$ \\
\hline Os hyperlinks de recursos e atividades complementares não funcionam & 1 & $2 \%$ \\
\hline A página é indicada como não segura pelo navegador de internet & 1 & $2 \%$ \\
\hline $\begin{array}{c}\text { O idioma de algumas ferramentas, como o GoToMeeting, não é o } \\
\text { português }\end{array}$ & 1 & $2 \%$ \\
\hline Ao inserir meu cadastro e senha, é comum haver falha de identificação & 0 & $0 \%$ \\
\hline As dúvidas postadas no AVA não são respondidas em tempo hábil & 0 & $0 \%$ \\
\hline
\end{tabular}


Na época da coleta de dados, 38 alunos (76\%) declararam não ter dificuldades em manipular o AVA. Outros 12 (24\%) reportaram dificuldades variadas (Tabela 7), fato talvez acentuado por estarem no primeiro semestre do curso. Entretanto, poucos mencionaram dúvidas nos encontros presenciais ou virtuais.

Grande parte das dificuldades reconhecidas nas respostas ao questionário envolviam a utilização de ferramentas de comunicação e o design do AVA (Tabela 7). Alguns alunos já haviam relatado, em encontros virtuais, empecilhos no uso das videoconferências, devido à conexão de internet lenta. Segundo Tenório et al. (2014b), falta de qualidade na conexão de internet pode desestimular, ou mesmo inviabilizar o uso de algumas TICs.

Tabela 8: Sugestões para facilitar a aprendizagem no AVA.

\begin{tabular}{c|r|r}
\hline Sugestões para facilitar a aprendizagem no AVA & Total & Percentual \\
\hline Oferecimento de listas de exercícios com respostas on-line & 32 & $64 \%$ \\
\hline Exercícios com feedback & 31 & $62 \%$ \\
\hline Troca mais ativa de mensagens com o tutor & 29 & $58 \%$ \\
\hline Disponibilidade de videoaulas detalhadas sobre todos os tópicos & 20 & $40 \%$ \\
\hline Acesso livre a rede sem fio na instituição ou no polo & 20 & $40 \%$ \\
\hline Troca mais ativa de mensagens com os colegas de curso & 19 & $38 \%$ \\
\hline Facilidade no acesso às ferramentas de comunicação no AVA & 14 & $28 \%$ \\
\hline Disponibilização de uma melhor configuração das páginas AVA & 9 & $18 \%$ \\
\hline Disponibilização de hyperlinks para aprofundar o conhecimento em cada & 9 & $18 \%$ \\
\hline tópico do curso & 9 & $18 \%$ \\
\hline Fornecimento de suporte para dúvidas sobre informática & 4 & $8 \%$ \\
\hline Substituição do sistema de gerenciamento do AVA pelo Moodle & 1 & $2 \%$ \\
\hline Possibilidade de usar o AVA com o Android & 1 & $2 \%$ \\
\hline Oferecer downloads para acesso em smartphones off-line & 1 & $2 \%$ \\
\hline
\end{tabular}

Os alunos fizeram diversas sugestões para facilitar a aprendizagem no AVA (Tabela 8). As duas principais foram de que se oferecessem listas de exercícios com 
respostas on-line $(32 ; 64 \%)$ e de que se fizesse o retorno (feedback) das correções dos exercícios (31,62\%), o que proporcionaria maior interação e uma avaliação contínua da construção do conhecimento pelo aluno. Belloni (2009), Hackmayer e Bohadana (2014) e Palloff e Pratt (2002) afirmam a importância de o tutor fornecer feedbacks constantes aos alunos.

Outras sugestões foram troca mais ativa de mensagens com o tutor, disponibilização de videoaulas detalhadas sobre todos os tópicos do curso, acesso livre a rede sem fio no polo e troca mais ativa de mensagens entre os colegas de curso.

Embora os alunos estivessem em um curso a distância, a maioria não tinha hábito de debater dúvidas, talvez por serem calouros. Assim, as trocas de mensagens com o tutor e com os colegas não eram tão frequentes, o que impedia a aprendizagem colaborativa. Diversos autores apontam a importância da interação para a construção coletiva do conhecimento na EaD contemporânea (Belloni, 2009; Palloff, \& Pratt, 2002).

Tabela 9: Avaliação da interação a distância com o tutor no AVA.

\begin{tabular}{c|r|r}
\hline Interação a distância com o tutor & Total & Percentual \\
\hline Positiva, pois o tutor facilita a busca de informações & 20 & $40 \%$ \\
\hline Positiva, pois considero importante debater o conteúdo com o tutor & 21 & $42 \%$ \\
\hline $\begin{array}{c}\text { Positiva, pois o tutor incentiva a troca de experiências e compartilha } \\
\text { sua vivência }\end{array}$ & 19 & $38 \%$ \\
\hline Positiva, pois o tutor está sempre disponível & 14 & $24 \%$ \\
\hline Positiva, pois há alguém para ajudar-me com dúvidas e preocupações & 16 & $32 \%$ \\
\hline Regular, pois não tenho tempo para frequentar diariamente o AVA & 9 & $18 \%$ \\
\hline Regular, pois a interação é mais difícil pelo AVA & 6 & $12 \%$ \\
\hline Regular, pois gostaria de que minhas questões fossem respondidas de \\
forma mais ágil & 7 & $14 \%$ \\
\hline Regular, pois não tenho vontade de interagir com pessoas & 0 & $0 \%$ \\
\hline Ruim, pois sinto-me pressionado a estudar & 0 & $0 \%$ \\
\hline Ruim, pois não simpatizo com o tutor & 0 & $0 \%$ \\
\hline Suim, pois considero o tutor pouco competente & 1 & $2 \%$ \\
\hline
\end{tabular}


Ao todo, 34 (68\%) alunos descreveram como positiva a interação a distância com o tutor; 13 (26\%) achavam-na regular e um (2\%), ruim. A maioria dos alunos considerou positiva essa interação com o tutor (Tabela 9), por ele debater os conteúdos (42\%), facilitar a busca de informações (40\%), promover a troca de experiências (38\%), ajudar a sanar dúvidas (32\%) e ser acessível (24\%). Na EaD contemporânea, o tutor deve atuar como facilitador, orientador e motivador da aprendizagem de cada aluno, além de estimular a interação entre os participantes do curso, como afirmam também Belloni (2009) e Bernardino (2011).

Seis alunos, que também assinalaram ter dificuldades em empregar ferramentas de comunicação (Tabela 7), achavam difícil interagir pelo AVA (Tabela 9).

Sobre a interação a distância com os colegas, 37 (74\%) alunos reputaram-na como positiva e 11 (22\%) consideraram-na regular. Nenhum a descreveu como ruim. A maioria percebia a interação com colegas como positiva por permitir debate de conteúdos $(25 ; 50 \%)$, troca de experiências ( $25 ; 50 \%)$ e compartilhamento de dúvidas e ansiedades (24; 48\%). A metodologia do curso prevê a aprendizagem colaborativa; logo, a interação entre os alunos era, de fato, muito importante. Diversos autores (Farias, 2010; Machado, 2009; Villardi, \& Oliveira, 2005) preconizam a interação como essencial para a aprendizagem em cursos a distância. Dentre os alunos que participaram da pesquisa, dois alunos só interagiam com o tutor e os colegas fora do AVA.

Tabela 10: Principais benefícios do AVA segundo os alunos.

\begin{tabular}{c|r|r}
\hline Principais benefícios do AVA do curso & Total & Percentual \\
\hline Oferecer formas de comunicação e interação com o tutor & 12 & $24 \%$ \\
\hline Oferecer formas de comunicação e interação com os colegas & 20 & $40 \%$ \\
\hline Proporcionar um espaço para troca de informações & 29 & $58 \%$ \\
\hline Disponibilizar hyperlinks interessantes & 12 & $24 \%$ \\
\hline Disponibilizar exercícios & 16 & $32 \%$ \\
\hline Disponibilizar feedbacks do tutor sobre as avaliações & 4 & $8 \%$ \\
\hline Armazenar materiais didáticos, tarefas e discussões & 21 & $42 \%$ \\
\hline Promover autonomia de aprendizagem & 20 & $40 \%$ \\
\hline Direcionar a aprendizagem de acordo com os encontros presenciais & 1 & $2 \%$ \\
\hline
\end{tabular}


Nas percepções dos alunos, os principais benefícios do AVA (Tabela 10) seriam oferecer um espaço para a troca de informações, armazenar materiais didáticos, tarefas e discussões, oferecer formas de comunicação e interação com os colegas, e promover a autonomia de aprendizagem. Vários desses benefícios foram arrolados pelos alunos como fatores facilitadores da aprendizagem a distância (Quadro 1).

Tabela 11: Principais características negativas do AVA.

\begin{tabular}{|c|c|c|}
\hline Principais características negativas do AVA & Total & Percentual \\
\hline Não permite a comunicação imediata com o tutor & 32 & $64 \%$ \\
\hline Não permite a comunicação imediata com os colegas de curso & 8 & $16 \%$ \\
\hline Meu aprendizado é de minha total responsabilidade & 7 & $14 \%$ \\
\hline Meu aprendizado depende de minha autonomia & 5 & $10 \%$ \\
\hline Tem design confuso & 10 & $20 \%$ \\
\hline Não é tão interativo e dinâmico & 7 & $14 \%$ \\
\hline Os materiais de estudo não possuem boa qualidade & 1 & $2 \%$ \\
\hline Os materiais de estudo não respondem às minhas dúvidas & 9 & $18 \%$ \\
\hline $\begin{array}{l}\text { Há pouca variedade de ferramentas de comunicação, como bate-papos, } \\
\text { fóruns de discussão e videoconferências }\end{array}$ & 4 & $8 \%$ \\
\hline As discussões acrescentam pouco ou nada à minha aprendizagem & 2 & $4 \%$ \\
\hline $\begin{array}{l}\text { A secretaria não tem um hiperlink nem responde a dúvidas ou } \\
\text { solicitações pelo AVA }\end{array}$ & 5 & $10 \%$ \\
\hline
\end{tabular}

Segundo os alunos, a principal característica negativa do AVA era não permitir a comunicação imediata com o tutor (Tabela 11). Embora houvesse, disponíveis, ferramentas capazes de possibilitar tal comunicação, como a videoconferência e o batepapo, elas eram usadas em momentos específicos, agendados pelo tutor.

\section{Considerações Finais}


Na EaD contemporânea, os AVAs são empregados frequentemente como salas de aula virtuais para facilitar o processo de ensino-aprendizagem e aproximar os participantes de um curso (Brasil, 2007).

O AVA - baseado no sistema Canvas - de um curso a distância de graduação em Engenharia foi analisado a partir das percepções de 50 calouros. Os alunos tinham um encontro presencial no laboratório de informática do polo a cada 15 dias e um encontro virtual nas semanas intercaladas. Durante alguns encontros presenciais e virtuais, foram feitas observações sobre o desempenho e as dificuldades dos alunos no uso do AVA e de suas ferramentas. Os alunos responderam ainda a um questionário sobre sua utilização.

Nos primeiros contatos com o AVA, os alunos relataram problemas de acesso, incompatibilidades na configuração do áudio e dificuldades em permanecer conectados às videoconferências nos encontros virtuais. Todavia, os problemas técnicos foram amenizados no decorrer do curso. Após quatro meses do início da graduação, apenas 12 alunos ainda reportaram dificuldades, em relação às ferramentas de comunicação e ao design do AVA.

Quase todos os alunos acessavam o AVA semanalmente. Eles o viam como um recurso promotor da construção do conhecimento, por facilitar o acesso à informação e fornecer flexibilidade. Para os alunos, os principais benefícios do AVA eram a disponibilização de um espaço para a troca de informações, o armazenamento de materiais didáticos, tarefas e discussões e o oferecimento de formas de comunicação e interação com os colegas. Já a característica negativa mais citada foi a impossibilidade de comunicação imediata com o tutor. As expectativas ao empregar o AVA eram, sobretudo, utilizar uma forma de aprendizagem alternativa ao estudo presencial e acessar conteúdos disciplinares adicionais.

Os alunos aproveitavam recursos variados para trabalhar conteúdos didáticos, por exemplo: textos complementares, portfólio, Youtube, fórum, e-mail, Google Drive e videoconferência. Apesar de o AVA já possuir inúmeros recursos, os alunos sugeriram que houvesse listas de exercícios com respostas on-line e exercícios com feedback.

Para a comunicação, os alunos utilizavam, predominantemente, e-mail, fórum, correio de mensagens do AVA, bate-papo e videoconferência. A maioria percebia a interação a distância, tanto com o tutor quanto com os colegas, como positiva, pois facilitava debates de conteúdos e trocas de experiências. 
Investigar as percepções de usuários de AVAs permite identificar seus aspectos positivos e negativos. Conhecer tais fatores pode ajudar a melhorar o aproveitamento e a gestão de cursos a distância.

\section{Agradecimentos}

Ao Laboratório de Novas Tecnologias da Universidade Federal Fluminense (Lante/UFF) e à Universidade Aberta do Brasil (UAB).

\section{Referências Bibliográficas}

Barbosa, S. D. J., \& Silva, B. S. (2011). Interação humano-computador. Rio de Janeiro: Sindicato nacional de editores de livros.

Bardin, L. (1998). Análise de conteúdo. Lisboa: Edições 70.

Belloni, M. L. (2002). Ensaio sobre a educação a distância no Brasil. Educação \& Sociedade, Campinas, XXIII(78), 131-148.

Belloni, M. L. (2005). O que é mídia-educação? A mediação escolar indispensável para a cidadania ( $2^{\mathrm{a}}$ ed.). Campinas: Autores Associados.

Belloni, M. L. (2009). Educação a distância ( $5^{a}$ ed.). Campinas: Autores Associados.

Bernardino, H. S. (2011). A tutoria na EaD: os papéis, as competências e a relevância do tutor. Revista Paidéi@: Revista Científica de Educação a Distância da Universidade Metropolitana de Santos, 2(4). Disponível em

http://revistapaideia.unimesvirtual.com.br/index.php?journal=paideia\&page=arti cle\&op =view\&path[]=166\&path[]=171

Bévort, E., \& Belloni, M. L. (2009). Mídia-educação: conceito, histórias e perspectivas. Educação \& Sociedade, 30(109), 1082-1084. Disponível em http://www.scielo.br/pdf/es/v30n109/v30n109a08.pdf

Bezerra, J. C. C., \& Brito, S. O. (2013). Portais educacionais: uma experiência do projeto e-jovem com sua metodologia voltada para o ensino em tecnologias da informação 
e comunicação (TICs) com o auxílio das plataformas Educandus e Moodle. In V Seminário Internacional de Educação a Distância. Belo Horizonte. Disponível em https://www.ufmg.br/ead/seminario/anais/pdf/Eixo 3.pdf

Brasil. (2007). Referenciais para elaboração de material didático para EaD no Ensino Profissional e Tecnológico. Brasília: Ministério da Educação e Cultura.

Brito, M. S. S. B. (2003). Educação e tecnologia: trilhando caminhos. Salvador: Uneb.

Câmara, R. H. (2013). Análise de conteúdo: da teoria à prática em pesquisas sociais aplicadas às organizações. Revista Interinstitucional de Psicologia, 6(2), 179-191.

Campos, F. C. A., Costa, R. M., \& Santos, N. (2007). Fundamentos da educação a distância, mídias e ambientes virtuais. Juiz de Fora: Editar.

Dias, R. F. (2003). Ambientes virtuais de aprendizagem: uma metodologia para avaliação de software. Dissertação de mestrado. Universidade Federal de Santa Catarina.

Farias, E. V. (2010). O tutor na Educação a Distância: a construção de conhecimentos pela interação nos ambientes midiáticos no contexto da educação libertadora. Scientia FAER, 2(2). Disponível em

http://www.uniesp.edu.br/faer/revistafaer/artigos/edicao2/elisio.pdf

Farias, S. C. (2013). Os benefícios das tecnologias de informação e comunicação (TIC) no processo de educação a distância (EAD). Revista digital de biblioteconomia e ciência da informação, 11(3), 15-29.

Gaspar, M. (2003). A arte rupestre no Brasil ( $2^{\text {a }}$ ed.). Rio de Janeiro: Jorge Zahar.

Gil, A. C. (1999). Métodos e técnicas de pesquisa social ( $5^{\mathrm{a}}$ ed.). São Paulo: Atlas.

Gutierrez, O. L. B. (2006). A educação a distância, o uso de novas tecnologias e a ênfase no audiovisual. Revista Global Manager, 7(11), 77-87.

Hackmayer, M. B., \& Bohadana, E. (2014). Professor ou tutor: uma linha tênue na docência em EAD. RIED: Revista Iberoamericana de Educación a Distancia, 17(2), 223-240. Disponível em

http://ried.utpl.edu.ec/sites/default/files/files/file/archivo/volumen17-2/ried172.pdf 
Kenski, V. M. (2004). Tecnologias e ensino presencial e a distância ( $4^{\mathrm{a}}$ ed.). Campinas: Papirus.

Lévy, P. (2003). O que é o Virtual? ( $1^{\text {a }}$ ed.). Rio de Janeiro: Editora 34.

Machado, S. A. (2009). As ferramentas de comunicação em educação a distância: estudo de caso do portal educação. Dissertação de mestrado. FAE Centro Universitário.

Maia, C. (2002). Guia brasileiro de Educação a Distância. São Paulo: Esfera.

Marconi, M. A., \& Lakatos, E. M. (2003). Fundamentos da metodologia científica ( $5^{\mathrm{a}}$ ed.). São Paulo: Atlas.

Messa, W. C. (2010). Utilização de ambientes virtuais de aprendizagem - AVAs: a busca por uma aprendizagem significativa. Revista Brasileira Aberta e a Distância, 9, 149.

Nascimento, R. B., \& Filho, N. T. (2002). Correio eletrônico como recurso didático no ensino superior: o caso da Universidade Federal do Ceará. Revista da Ciência da Informação, 31(2), 86-97.

Palloff, R. M., \& Pratt, K. (2002). Construindo comunidades de aprendizagem no ciberespaço: estratégias eficientes para a sala de aula on-line. Porto Alegre: Artmed.

Ribeiro, E. N., Mendonça, G. A. A., \& Mendonça, A. F. (2007). A importância dos ambientes virtuais de aprendizagem na busca de novos domínios da EAD. In XIII Congresso Internacional da Associação Brasileira de Educação a Distância. Curitiba. Disponível em http://www.abed.org.br/congresso2007/tc/4162007104526am.pdf

Santos, M. C. D. (2011). Importância da comunicação na EaD virtual: enfoque conceitual e dialógico. In XVII Congresso Internacional da Associação Brasileira de Educação a Distância. Manaus. Disponível em http://www.abed.org.br/congresso2011/cd/67.pdf

Sousa, R. P., Moita, F. M. C. S. C., \& Carvalho, A. B. G. (2011). Tecnologias digitais na educação. Campina Grande: Editora EDUEPB. 
Teixeira, N., Sales, N. A., Tenório, T., \& Tenório, A. (2015). As competências socioafetivas aceitação e honradez segundo a percepção de tutores a distância. RIED: Revista Iberoamericana de educación a Distancia, 18(1), 129-149. Disponível em http://ried.utpl.edu.ec/sites/default/files/files/pdf/v\%20181 /art6 ascompetencias.pdf

Tenório, A., Souto, E. V., \& Tenório, T. (2014a). Percepções sobre a competência socioafetiva de cordialidade e a humanização da tutoria a distância. EAD em foco: Revista Científica em Educação a Distância, 4(1), 36-47. Disponível em http://eademfoco.cecierj.edu.br/index.php/Revista/article/view/199/48

Tenório, A., Ferreira, R. S. L., Almeida, M. C. R., Zucon, L. H., \& Tenório, T. (2014b). Ferramentas da educação a distância: a visão do tutor. EAD em foco: Revista Científica em Educação a Distância, 4(1), 48-60. Disponível em http://eademfoco.cecierj.edu.br/index.php/Revista/article/view/204/49

Trabucho, I. V. (2008). Da massificação da leitura à globalização da internet. Espanha: Salamanca.

Valentini, C. B., \& Soares, E. M. S. (2010). Aprendizagem em ambientes virtuais: compartilhando ideias e construindo cenários ( $2^{\mathrm{a}}$ ed.). Rio Grande do Sul: Educs.

Villardi, R., \& Oliveira, E. G. (2005). Tecnologia na educação: uma perspectiva sociointeracionista. Rio de Janeiro: Dunya. 